\title{
Electrophoresis of Modified Collagen
}

\author{
By James M. Cassel and Joseph R. Kanagy
}

Electrophoretic studies were made on collagen samples that were modified by a variety of treatments. The isoelectric point of collagen heated at $140^{\circ} \mathrm{C}$ in air is $\mathrm{pH} 5.3$, and that of collagen shrunken by heating in water is $\mathrm{pH} 5.2$, as compared with $\mathrm{pH} 7.0$ for the untreated collagen. Deaminized collagen was isoelectric at $\mathrm{pH} 4.6$.

The isoelectric point of purified collagen was lowered by tanning with basic chromium sulfate solutions. Samples were tanned to contain 0.6-, 1.0-, 1.8-, and 2.5-percent of chromium expressed as chromic oxide. A maximum shift in isoelectric point was observed with a sample in which 1.8-percent of chromic oxide was fixed. Chrome tanning a deaminized collagen sample had only a small effect on the isoelectric point. A vegetable-tanned leather and vegetable-tanned collagen were isoelectric at $\mathrm{pH}$ 3.2. Chrome retanning a vegetabletanned collagen did not affect its isoelectric point.

The electrophoretic behavior of tanned collagen is compared with that of unstretched nylon.

\section{Introduction}

Electrophoretic techniques have been frequently used to investigate the properties of protein surfaces. Excellent discussions and reviews of the general subject have been presented by Abramson [1], ${ }^{1}$ by Abramson, Moyer, and Gorin [2], and by Moyer [3].

Collagen contains a number of reactive groups capable of fixing acid and base. Undoubtedly these reactive groups play an important role not only in combining with acid or base but also in the combination that occurs with formaldehyde, tannins, and dyes. It was believed that some fundamental information in regard to the mechanism of these reactions might be obtained from an electrophoretic study. In a publication now in press [4] the authors have described the electric mobility measurements made on collagen samples prepared in various ways. It is the purpose of this paper to present similar measurements on collagen samples that have been modified by heating, water shrinking, deaminizing, protracted ball mill grinding, and by several tanning processes. The tanning processes included vegetable,

\footnotetext{
1 Figures in brackets indicate the literature references at the end of this
} paper. chrome, formaldehyde, and vegetable followed by chrome.

\section{Materials}

It was believed that a better understanding of the tanning mechanism could be obtained by tanning a material that had not been degraded and that contained for the most part pure collagen. For this reason collagen purified as recommended by Highberger [5] rather than commercial hide powder was used as a standard from which changes in electrophoretic characteristics could be estimated. With one exception the modified collagen samples were prepared from this purified collagen. The exception was a sample of vegetable-tanned leather.

\section{Preparation of Modified Collagens}

Chrome-tanned samples were prepared by tanning collagen in solutions of several concentrations of basic chromium sulfate. Previous to tannage, the collagen was ground to a uniform particle size in a Wiley mill. Approximately $20 \mathrm{~g}$ was then added to cold distilled water in a glassstoppered bottle and allowed to soak overnight. The tan liquor was prepared by leaching a weighed 
amount of the crude commercial form of basic chromium sulfate in water and filtering off the insoluble material. This liquor was transferred to the bottle containing collagen and water, and the chromic salt-collagen mixture was agitated for 24 to $30 \mathrm{hr}$, during which time no adjustment of $\mathrm{pH}$ was made. The tanned sample was thoroughly washed in changes of distilled water, dehydrated in successive changes of alcohol and ether, and air-dried. Chromium was determined on the air-dried material by the perchloric acid method.

A portion of deaminized collagen, prepared by the method of Thomas and Foster [6], was treated in the same manner as collagen with a basic chrome tanning solution. A determination of chromium by the perchloric acid method showed that deaminized collagen fixed 83 percent as much chromium as did collagen when treated under the same conditions.

Two types of vegetable-tanned materials were studied. These were commercially tanned leather and laboratory tanned collagen samples. The commercial leather was ground in a Wiley mill, degreased in petroleum ether, air-dried, and reground in the Wiley mill to pass a 60-mesh screen. In the laboratory tannage, collagen was treated with two concentrations of chestnut tannin. Two 20-g portions of collagen were soaked overnight in cold water contained in glass stoppered bottles. The chestnut extracts containing 20 and $40 \mathrm{~g}$ of tannin per $350 \mathrm{ml}$ of water were added to the collagen water mixtures, and the contents were agitated 24 to $30 \mathrm{hr}$ on a shaker. The materials were then thoroughly washed in distilled water and dehydrated in successive changes of alcohol and ether. They were then reground in a Wiley mill to pass the 60 -mesh screen.

A vegetable-chrome tanned sample was prepared by treating a portion of the vegetabletanned collagen with chrome-tanning solution according to the method previously described. The sample fixed 0.5-percent chromium expressed as chromic oxide.

Formaldehyde-tanned collagen samples were prepared by the method suggested by Highberger and Retzsch [7], with the exception that the material was washed thoroughly in changes of 0.1 $M$ phosphate buffer before washing in several changes of distilled water. It was then dehydrated in alcohol and ethyl ether.
To determine whether the grinding action of a ball mill had any effect on collagen, a sample (previously ground in a Wiley mill) was pulverized to a fine powder in the ball mill. At various intervals, specimens were removed from the mill for mobility measurements.

Water-shrunken samples were obtained by heating collagen powder for $5 \mathrm{~min}$ in water at $65^{\circ} \mathrm{C}$. The material was dried by successive alcohol and ether extractions and then reground in the Wiley mill to pass the 60 -mesh screen.

The effect of exposing collagen to moderately high temperatures was studied by drying collagen samples in a Brabender moisture apparatus at $140^{\circ} \mathrm{C}$ for 1 day and 4 days, respectively. The loss in moisture was followed with the built-in weighing mechanism of the oven.

\section{Determination of Electrical Mobilities}

The electrophoresis cell employed in this work is the horizontal microelectrophoresis cell like the one used by Abramson [8]. A description of the technique to be used with this type of cell is given by Moyer [9]. With the exception of the samples used in the study of the effect of the ball mill, the modified collagens were ground in a Wiley mill until the powder formed passed through a 60 mesh sieve. The powder was agitated in a buffer by using a Waring blendor, and after the large particles were allowed to settle to the bottom, the upper portion was decanted. The finer particles remained suspended in the liquid for several hours.

The ionic strength of all buffers was 0.005 . The buffer mixtures used were as follows: $\mathrm{pH} 2.4$ to 3.6, potassium chloride-hydrochloric acid; $\mathrm{pH} 4.0$ to 5.6 , sodium acetate-acetic acid; $\mathrm{pH} 6.0$ to 7.8 disodium phosphate-dihydrogen phosphate; pH 8.0 to 9.2 boric acid-borax; $\mathrm{pH} 10.0$ sodium hydroxide-boric acid-potassium chloride. The specific resistance of solutions introduced into the cell was determined with a pipette conductivity cell and a conductivity bridge [9]. Two or three groups of measurements, each consisting of at least ten measurements of the velocities of the particles, were made at each selected $\mathrm{pH}$.

All mobility measurements were made in a room at approximately $23^{\circ} \mathrm{C}$, and the values were corrected to $25^{\circ} \mathrm{C}$ by applying a factor of 2 percent per degree [9]. 


\section{Results and Discussion}

The results obtained by determining the $\mathrm{pH}-$ mobility curves for the collagens modified in several ways are presented, and their significance is discussed.

\section{Effect of Chrome Tanning}

The change in the isoelectric point of collagen caused by chrome tannage has been followed by Gustavson [10] and Theis [11]. In both investigations additional ions were introduced into the medium with the formation of a more complicated system than is expedient for such a study. In the present work collagen samples were tanned to contain 0.6-, 1.0-, 1.8-, and 2.5-percent chromium expressed as chromic oxide, and the tanning was done with no extraneous ions present. The $\mathrm{pH}-$ mobility curves are shown in figure 1 for the tanned and untanned materials.

The isoelectric point of the untanned material is higher than the isoelectric point of any of the tanned samples. There are several possible mechanisms that would explain such a difference in isoelectric point. If the amino groups of the collagen were inactivated through combination with the complex chromium ions, the effect would be to make the net charge of the collagen more negative and result in a lowering of the isoelectric point. There is also the possibility that the complex chromium ions combine with the collagen in some other way so that highly negative charges are imparted to the protein surface with the net result that the isoelectric point of the product is lowered.

In addition to these two possible mechanisms, a third has been suggested that proposes that the chromium combines with both amino and carboxyl groups [11]. Equivalent inactivation of both groups would lower the isoelectric point since the basic groups of the protein are supposedly stronger [12]. Although such a mechanism would lower the isoelectric point, there is some doubt that it would cause the large shift from $\mathrm{pH} 7.0$ to $\mathrm{pH} 4.2$.

The results shown in figure 1 indicate that a maximum shift in isoelectric point occurred with a sample that contained 1.8-percent chromium expressed as chromic oxide. It is possible that the initial take-up of chromium (up to $1.8 \%$ ) represents a different process than that which occurs in the pick-up of additional chromium.

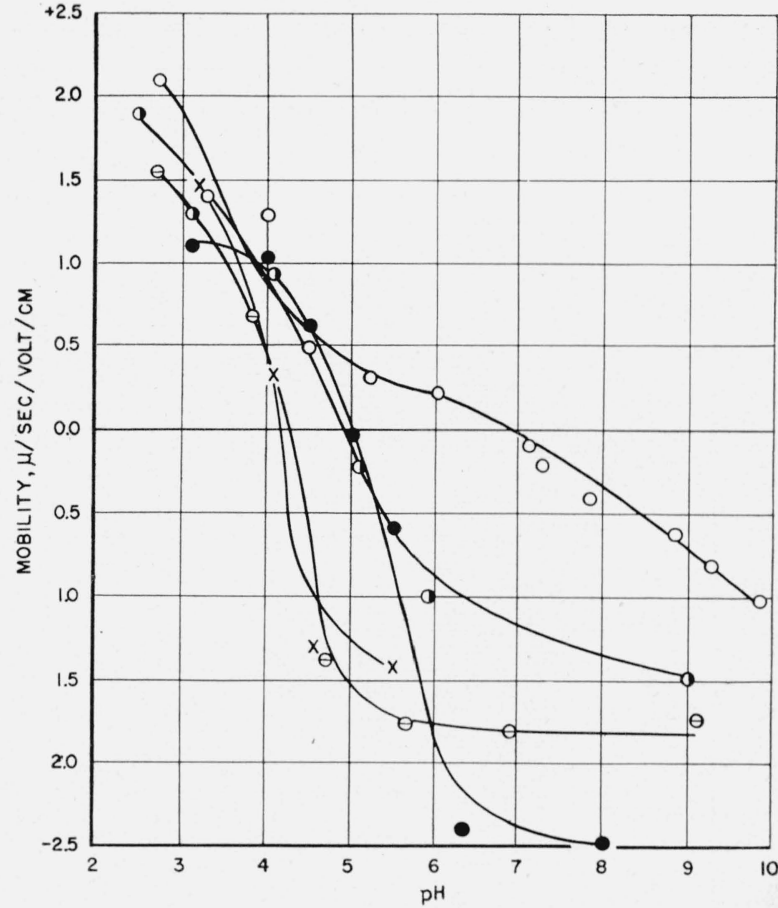

Figure 1. Effect of chrome tanning on the pH-mobility curve of collagen.

, 0.0-percent $\mathrm{Cr}_{2} \mathrm{O}_{3} ;$, 0.6-percent $\mathrm{Cr}_{2} \mathrm{O}_{3} ; \ominus, 1.0$-percent $\mathrm{Cr}_{2} \mathrm{O}_{3} ; \times, 1.8$ percent $\mathrm{Cr}_{2} \mathrm{O}_{3} ;$, 2.5-percent $\mathrm{Cr}_{2} \mathrm{O}_{3}$.

It may be that initially the complex chromium ions, which theoretically are present in both anionic and cationic form, combine predominantly with the amino groups of the collagen. After approximately 1.8-percent chromic oxide has been fixed, combination with the carboxyl groups of the collagen begins to play a more important part. Such a mechanism of tanning would result in a minimum isoelectric point with a certain content of fixed chromic oxide. It may be pointed out that if initial combination does occur between the complex chromium ions and the amino groups, then fixation of 1.8-percent chromic oxide would mean that two equivalents of chromium are combined with one equivalent of amino nitrogen.

Other results that have a bearing on the theory of chrome tanning are discussed later in this paper.

\section{Effect of Deaminization}

If a portion of the basic groups of collagen is removed by deaminization, the collagen should show a different and more acid isoelectric point, In figure 2 the $\mathrm{pH}$-mobility curve of the deami- 
nized material is compared with that of the untreated collagen.

The shift in isoelectric point to a lower $\mathrm{pH}$ (7.0 to 4.6$)$ is quite pronounced. These results support the theory that deaminization removes a portion of the basic groups of collagen.

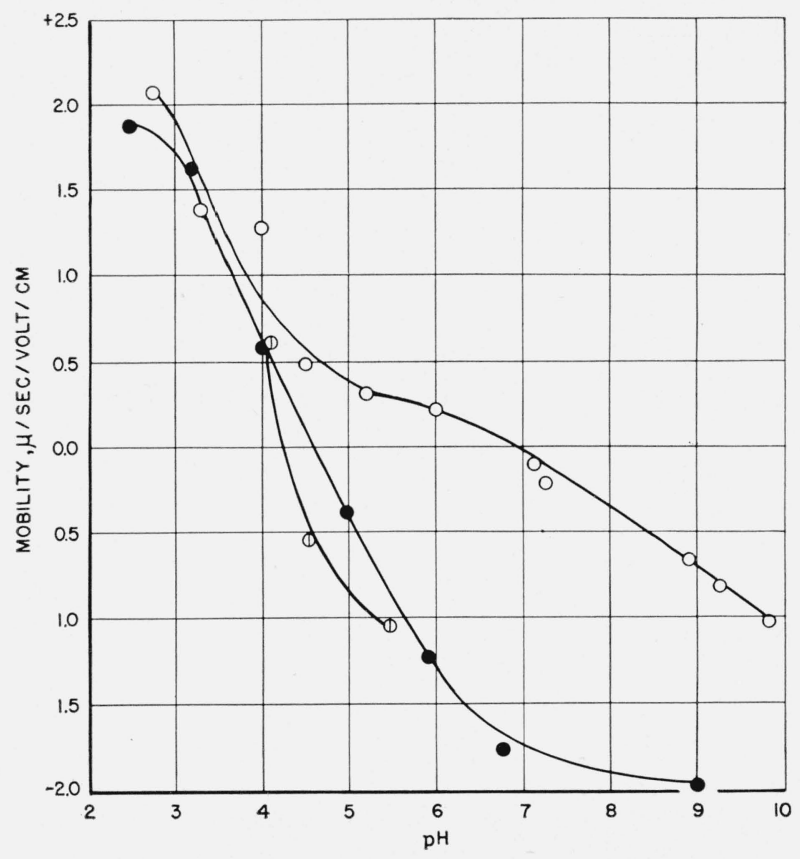

Figure 2. Effect of deaminization on the pH-mobility curve of collagen.

$\bigcirc$, Untreated; $\bullet$ deaminized; $\oplus$, deaminized-chrome tanned.

Thomas and Foster [6] located the isoelectric point of deaminized hide powder by the dye technique between $\mathrm{pH} 3.7$ and 4.2, which is a shift from the isoelectric point of 5.0 that they found for hide powder. Page and Holland [13] found that deaminized vegetable-tanned hide powder contained considerably less alkali resistant tannin, and they reasoned that it was the uncharged amino groups that were removed by deaminization.

Stiasny [14] has suggested that the change in hide substance upon deaminization is not due to purely chemical modifications but may be attributed to a change in its structure whereby the active surface has been decreased. However, in figure 2 that sharp slope of the $\mathrm{pH}$-mobility curve in the isoelectric region indicates that the deaminized material is as reactive as the untreated collagen, if not more reactive.

\section{Deaminization Followed by Chrome Tanning}

In 1926, Thomas and Kelly [15] suggested that if the basic groups of collagen play a role in chrome tanning, their removal by deaminization should markedly affect the fixation of chrome. By deaminizing hide powder and then retanning with basic chromium sulfate solutions, they found considerably less chromium fixed by the deaminized hide powder than by the untreated hide powder, and they concluded that the basic groups of collagen played a significant role in chrome tanning. Gustavson [16] carried out similar studies and stated that the diminished acid-combining capacity of the structurally altered hide powder was responsible for the inhibition of cationic chrome fixation by deaminized hide powder. In the present study it was found that deaminized collagen fixed 83 percent as much chromium as did the untreated collagen.

In figure 2 the $\mathrm{pH}$-mobility curves of deaminized and chrome-tanned deaminized collagen are compared with the mobility curve of untreated collagen. Treating the deaminized collagen with basic chrome tanning solution has resulted in a very slight change in isoelectric point from $\mathrm{pH}$ 4.6 to 4.3. Comparing the data of figures 1 and 2 , it will be observed that either deaminized collagen or untreated collagen, when treated to contain 1.5-percent chromic oxide, is isoelectric at $\mathrm{pH} 4.3$.

In figure 2 the very slight shift in isoelectric point caused by chrome tanning of deaminized collagen indicates that the charge of the chrome complex does not influence to any great extent the electrophoretic characteristics of the sample. This result greatly weakens the theory discussed in regard to the data of figure 1, which suggested that chrome tanning imparts highly negative charges to the collagen surface with the net result that the isoelectric point of the product is lowered. On the other hand the theory is strengthened that proposes that inactivation of the basic groups of collagen by the chrome-tanning solution is responsible for the large shifts in isoelectric point observed in figure 1.

\section{Effect of Vegetable Tanning}

In figure 3 the $\mathrm{pH}$-mobility curves are shown for collagen tanned with two concentrations of chestnut tannin, and for vegetable-tanned leather that had been degreased. 


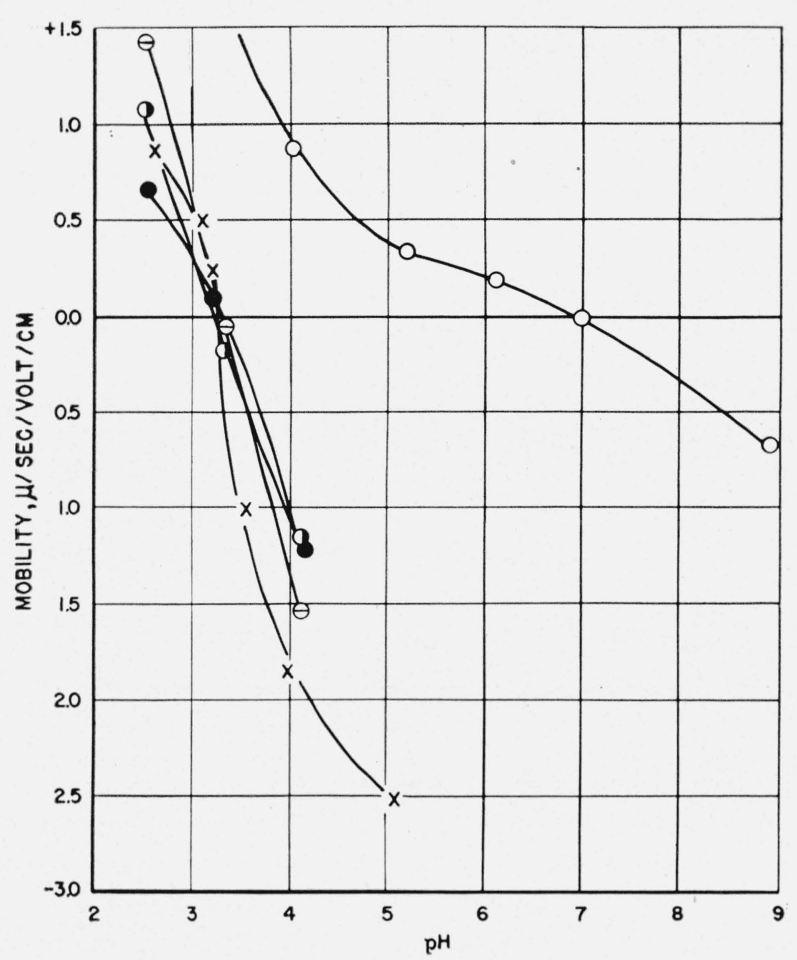

Figure 3. Effect of vegetable tanning on the $\mathrm{pH}$-mobility curve of collagen.

. Untanned collagen; $\ominus$, vegetable-tanned collagen ( $1 \mathrm{~g}$ of collagen per $1 \mathrm{~g}$ of tannin); vegetable-tanned collagen ( $1 \mathrm{~g}$ of collagen per $2 \mathrm{~g}$ of tannin); $\times$, vegetable-tanned leather; $\boldsymbol{O}$, vegetable-chrome tanned collagen.

The very close agreement in isoelectric point of the three samples leads one to believe that the dominant factor affecting the isoelectric point of vegetable-tanned material is the vegetable tannin itself. This would be in agreement with the theory that from $\mathrm{pH} 2.5$ to 14.0 the vegetable tannin particles are negatively charged [17]. Adsorption of the vegetable tannin by the collagen would then produce a surface dominated by the negative charges of the tanning material. One would not expect much change in the surface by doubling the concentration of tanning material. This theory of the tanning mechanism does not rule out chemical combination between the amino groups of collagen and the negatively charged tannin particles. Rather, it is believed that this does occur, but the adsorption phenomenon overshadows this specific reaction.

In attempting to retan vegetable-tanned collagen with basic chromium sulfate, only 0.5-percent chromic oxide was fixed. The results in figure 3 show that this fixation of chromium had no effect on the isoelectric point of the vegetable- tanned collagen. The pick-up of the chromium has diminished the net charge on the surface in the extreme acid region. This again would indicate a surface that is predominantly that exhibited by vegetable tannin particles but which is altered slightly by the addition of the chrometanning material.

\section{Effect of Formaldehyde Tanning}

Tanning with 1-percent formaldehyde at $\mathrm{pH} 7.8$ lowered the isoelectric point of collagen from $\mathrm{pH}$ 7.0 to $\mathrm{pH} 4.6$ (see fig. 4).

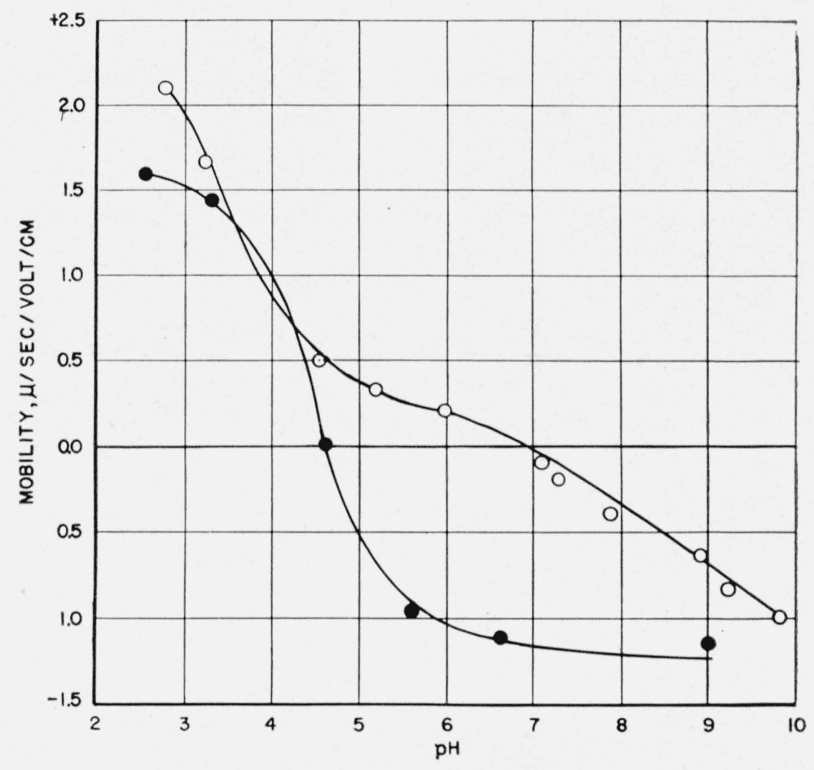

FIGURE. 4. Effect of formaldehyde tanning on the $\mathrm{pH}-$ mobility curve of collagen.

$\bigcirc$, Untanned; $\bullet$, formaldehyde tanned.

Since there is no reason to suspect, as in the case of chrome tanning, that the formaldehyde molecules would contribute to the net charge of the tanned product, we can be reasonably sure that the change in isoelectric point is due to inactivation of ionizable protein groups. In this instance, since the isoelectric point has been lowered, the amino groups of collagen must be involved in the tanning action. This would agree with the majority of work that has been done on this subject [18], [19].

\section{Effect of Protracted Ball Mill Grinding}

Curves 1 and 3 of figure 5 represent the $\mathrm{pH}$ mobility data for two samples of hide collagen 
that had been ground in a Wiley mill until the material could be sifted through a 60 -mesh screen.

The difference in isoelectric point of the materials is attributed to the methods of preparation [4]. Curves 2 and 4 are for the two samples after they were powdered in a ball mill. The difference in the magnitude of the shifts of isoelectric point for the samples is probably due to the differences in time that the materials were ground in the ball mill (30 hr vs. $15 \mathrm{hr}$ ).

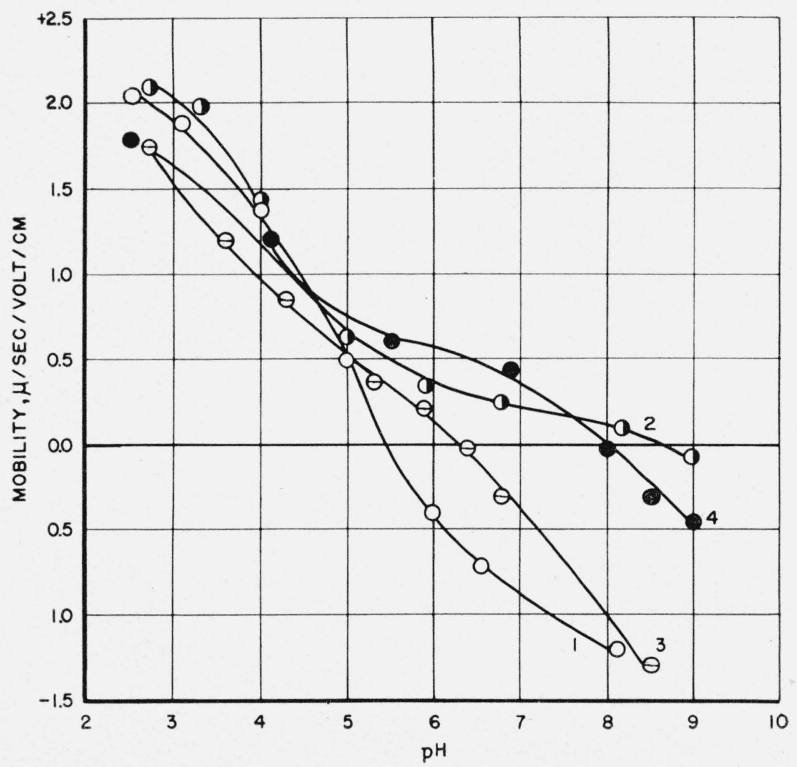

FIgURE 5. Comparison of the pH-mobility curves of collagens ground in the ball mill and in the Wiley mill.

Curve 1, sample A ground in Wiley mill; curve 2, sample A ground in ball mill for $30 \mathrm{hr}$; curve 3 , sample B ground in Wiley mill; curve 4, sample B ground in ball mill for $15 \mathrm{hr}$.

A similar shift in isoelectric point to a higher $\mathrm{pH}$ is shown in figure 6, which represents data obtained by determining the mobilities of samples ground for different periods of time in a ball mill.

Prior to pulverization in the ball mill, the collagen (ash content $0.1 \%$ ) was isoelectric at $\mathrm{pH}$ 6.3. The ash contents of the specimens removed from the ball mill after 4,12 , and $27 \mathrm{hr}$ of milling were $1.8,3.9$, and 4.2 percent, respectively. The results of figure 6 show that the latter two specimens of high ash content were isoelectric at a more alkaline $\mathrm{pH}$ than either the unpulverized collagen or that milled for $4 \mathrm{hr}$.

Cohen [20] has shown that dry grinding of numerous proteins produces definite irreversible changes in protein molecules. He found that

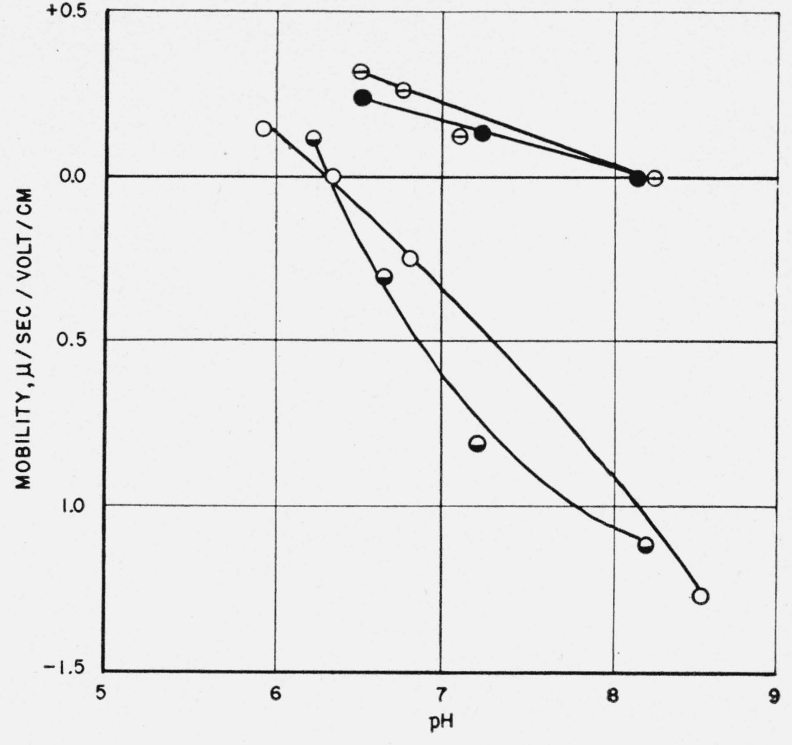

Figure 6. Comparison of the pH-mobility curves of collagens ground for different periods of time in the bull mill. $\bigcirc$, Untreated; $\ominus, 4 \mathrm{hr} ; \ominus, 12 \mathrm{hr} ; \bullet, 27 \mathrm{hr}$.

collagen yielded some water soluble protein after having been ground in a ball mill, and he concluded that dry grinding is a physical agent that produces changes that are associated with denaturation. Routh [21] has pointed out that at the point of contact of the balls a large amount of energy as heat may be liberated and that this may be one of the factors influencing the changes produced in proteins ground in this fashion. It has been shown that heat denaturation of soluble proteins, such as albumin, causes a shift in isoelectric point of these substances to a more alkaline $\mathrm{pH}$ [2]. In contrast to the shift in isoelectric point to higher $\mathrm{pH}$ observed with soluble protein, work reported later in this paper shows that exposure of collagen to rather high temperature actually lowers the isoelectric point. However, it is believed that some heat denaturation of the collagen occurs but that this denaturating effect is compensated for by another factor, namely that due to the presence of mineral ash.

The increase in ash content of the collagen upon grinding in the ball mill is the result of a breakdown in the surface of the porcelain mill. The ash adsorbed by the collagen is siliceous matter containing potassium, aluminum, and magnesium. Adsorption of these basic ions would shift the isoelectric point to a more alkaline $\mathrm{pH}$. It is believed that the collagen sample ground $4 \mathrm{hr}$ was de- 
natured but adsorbed sufficient ash to compensate, and no change was produced in the electrophoretic characteristics of the product. As the grinding period is extended, the effect on the electrophoretic characteristics, due to the increased ash content, overbalances the effect due to denaturation, and the isoelectric point is shifted to a more alkaline region.

\section{Effect of Heating}

In figure 7 the $\mathrm{pH}$-mobility curves of collagen samples that have been heated in air and water are compared with the mobility curve of untreated collagen.

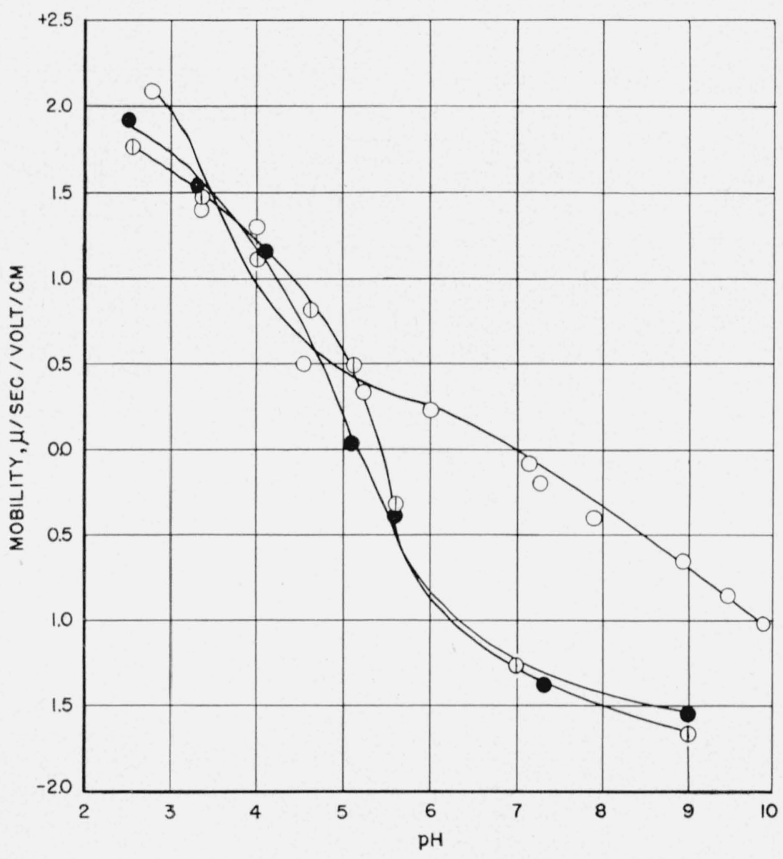

Figdre 7. Comparison of the pH-mobility curves of untreated, water shrunken, and dry heated collagen.

$\bigcirc$, Untreated; $\mathbb{\Phi}$, dry heated; $\bullet$, water shrunken.

From the results of Weir's work on the shrinkage of kangaroo tendon [22], it was estimated that collagen powder would be completely shrunken after 5 minutes' exposure to water at $65^{\circ} \mathrm{C}$. Astbury [23] has postulated that the thermal contraction of collagen is an example of the capacity of polypeptide chains to shorten by intramolecular folding. This collapsing of the chains upon themselves produces a change in the surface of the material. It is this change of purely a physical nature that is believed to be responsible for the shift in isoelectric point observed in figure 7 .
Abramson, Moyer, and Gorin [2] have pointed out that changes of a physical nature in a substance may lead to a decrease or increase in the adsorption of ions from a buffer medium and thus result in a marked shift in isoelectric point. It should be observed that the surface of the shrunken collagen is apparently very similar to that of gelatin, for the isoelectric point of gelatin made from purified collagen by heating in water at a high temperature is at $\mathrm{pH} 5.0$ [24].

In figure 7 the mobility curve of dry heated collagen represents data obtained from a sample heated 1 day at $140^{\circ} \mathrm{C}$. A portion of this sample was heated an additional 3 days at the same temperature, but no change in the electrophoretic characteristics of the material was observed. The weight loss of the collagen per 1 and 4 days was 19.0 and 19.6 percent, respectively. This loss in weight would indicate that more than moisture had been removed and that an actual breakdown of the sample had begun [25]. It is believed that the lower isoelectric point of the treated sample is the result of local shrinkage and that the surface of these collagen fibers resembles a great deal the surface of the collagen fibers that have been shrunken in water.

\section{Comparison of Tanned Collagen and Nylon}

One pertinent fact obtained by viewing the data is that the isoelectric point of many of the altered collagens was between pH 4.2 and 5.0. The fairly consistent change in isoelectric point to this $\mathrm{pH}$ region may be in some manner related to the structure of the collagen. Harris and Sookne [26] showed that the polyamide nylon, which has the following type of structure:

$$
\begin{array}{r}
-\mathrm{CO}-\mathrm{R}-\mathrm{CO}-\mathrm{NH}-\mathrm{R}^{1}-\mathrm{NH}-\mathrm{CO}-\mathrm{R}- \\
\mathrm{CO}-\mathrm{NH}-\mathrm{R}^{1}-\mathrm{NH}-,
\end{array}
$$

where $\mathrm{R}$ and $\mathrm{R}^{1}$ may represent 4 and 6 methylene $\left(-\mathrm{CH}_{2}-\right)$ groups, had an isoelectric point at $\mathrm{pH}$ 4.0. Nylon does not contain side chains with active basic or acidic groups. The amphoteric character of the polymer is attributed to what Harris and Sookne called amide groups but which are also known as peptide groups. If, during tanning, the free acid and basic groups of collagen were inactivated, the structure that remains is essentially similar to that of nylon, and such a material would be isoelectric near $\mathrm{pH}$ 4.0. Appar- 
ently in the case of vegetable tanning, fixation of tannin particles builds up a high negatively charged surface with the result that the isoelectric point is even lower than that shown by the nylon type structure.

\section{References}

[1] H. A. Abramson, Cold Springs Harbor Symposia, Quant. Biol. 1, 39 (1933).

[2] H. A. Abramson, L. S. Moyer, and M. H. Gorin, Electrophoresis of proteins (Rheinhold Publishing Corp., New York, N. Y., 1942).

[3] L. A. Moyer, Cold Springs Harbor Symposia, Quant. Biol. 6, 228 (1938).

[4] J. M. Cassel, J. R. Kanagy, J. Research NBS 42, (1949) RP1992.

[5] J. H. Highberger, J. Am. Leather Chem. Assn. 31, 93 (1936).

[6] A. W. Thomas and S. B. Foster, J. Am. Chem. Soc. 48, 489 (1926).

[7] J. H. Highberger and C. E. Retzsch, J. Am. Leather Chem. Assn. 34, 131 (1936).

[8] H. A. Abramson, Electrokinetic phenomena (Chemical Catalog Co., Inc., New York, N. Y., 1934).

[9] L. S. Moyer, J. Bact. 31, 531 (1936).

[10] K. H. Gustavson, Discussed in Stiasny's "Gerbereichemie" (Theodore Steinkopff, Dresden, 1931).

[11] E. R. Theis, J. Am. Leather Chem. Assn. 36, 459 (1941).
[12] W. E. Braybrooks, J. Int. Soc. Leather Trades Chem. 23, 73 (1939).

[13] R. O. Page and H. C. Holland, J. Am. Leather Chem. Assn. 32, 78 (1937).

[14] E. J. Stiasny, Gerbereichemie (Theodore Steinkopff, Dresden, 1931).

[15] A. W. Thomas and M. W. Kelly, J. Am. Chem. Soc. 48, 1312 (1926).

[16] K. H. Gustavson, J. Am. Leather Chem. Assn. 22, 236 (1927).

[17] A. W. Thomas and S. B. Foster, Ind. Eng. Chem. 15, 707 (1923).

[18] G. D. MeLaughlin and E. R. Theis, the chemistry of leather manufacture. (Rheinhold Publishing Corp., New York, N. Y., 1945).

[19] O. Gerngross and S. Bach, Collegium No. 631, 350 (1922); No. 644, 377 (1923).

[20] H. R. Cohen, Arch. Biochem. 2, 1 to 8 (1943).

[21] J. I. Routh, J. Biol. Chem. 135, 175 (1940).

[22] C. E. Weir, J. Research NBS 42, 17 (1949) RP 1947.

[23] W. T. Astbury. J. Int. Soc. Leather Trades Chem. 24, 69 (1940).

[24] J. Beek and A. Sookne, J. Research NBS 23, 271 (1939) RP1230; J. Am. Leather Chem. Assn. 34, 641 (1939).

[25] J. R. Kanagy, J. Am. Leather Chem. Assn. 35, 632 (1940); J. Research NBS $\mathbf{2 5 ,} 149$ (1940) RP1319.

[26] M. Harris and A. Sookne, J. Research NBS 26, 289 (1941) RP1376.

Washington, December 9, 1948. 